\title{
Article
}

\section{Identifying risk factors for mortality in patients admitted to hospital with COVID- 19}

Harrison, Joanna, Hill, James Edward and Palmer, Karen

Available at http://clok.uclan.ac.uk/38321/

Harrison, Joanna ORCID: 0000-0001-8963-7240, Hill, James Edward ORCID: 0000-0003-1430-6927 and Palmer, Karen (2021) Identifying risk factors for mortality in patients admitted to hospital with COVID-19. British Journal of Cardiac Nursing, 16 (6). ISSN 1749-6403

It is advisable to refer to the publisher's version if you intend to cite from the work. $10.12968 /$ bjca.2021.0029

For more information about UCLan's research in this area go to http://www.uclan.ac.uk/researchgroups/ and search for <name of research Group>.

For information about Research generally at UCLan please go to http://www.uclan.ac.uk/research/

All outputs in CLoK are protected by Intellectual Property Rights law, including Copyright law. Copyright, IPR and Moral Rights for the works on this site are retained by the individual authors and/or other copyright owners. Terms and conditions for use of this material are defined in the policies page.

\section{CLoK}

Central Lancashire online Knowledge www.clok.uclan.ac.uk

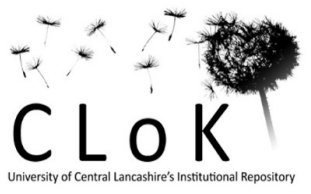




\section{Identifying risk factors for mortality in patients admitted to hospital with COVID-19}

An evidence summary based on the following systematic review: Tian, W, Jiang, W, Yao, J, et al. Predictors of mortality in hospitalized COVID-19 patients: A systematic review and metaanalysis. J Med Virol. 2020; 92: 1875- 1883. https://doi.org/10.1002/jmv.26050

Joanna Harrison ${ }^{(1)}$, James Hill ${ }^{(1)}$, Karen Palmer ${ }^{(2)}$. (1) University of Central Lancashire; (2) Lancashire and South Cumbria NHS Foundation Trust.

\section{Introduction}

There have been $112,456,453$ confirmed cases of Covid-19 worldwide resulting in 2,497,514 deaths (February 26,2021$)^{(1)}$. As a relatively new disease, little is known about the clinical predicators of COVID-19 specific mortality ${ }^{(2)}$. Previous reviews have focused on either severity of the disease ${ }^{(3,4)}$ or specific comorbidities ${ }^{(5,6)}$ linked to mortality, where in many cases the evidence has been limited. Subsequently, the systematic review by Tian et al. aims to re-evaluate the current body of evidence to comprehensively clarify predictors of mortality in hospitalised patients with COVID-19 ${ }^{(2)}$. This commentary aims to critically appraise the methods used within this systematic review and metaanalysis to discuss the findings in the context of current clinical practice.

\section{Methods}

A multi-database search was undertaken from January 1, 2020 to April 24, 2020 with no language restrictions. Additional searches of systematic reviews and eligible studies' citation lists were screened for eligible articles. No clear criteria were set for the population under examination based on the aims of the review. The patients needed to be hospitalised and have COVID-19 but there was no clear indication of how this was defined. Family-based studies and those which reported paediatric only cases were excluded, as were those which did not clearly report death as an outcome. Screening, data extraction and quality assessment (Agency for Healthcare Research and Quality (AHRQ)) were carried out by two independent reviewers. A random effects meta-analysis was undertaken to compare a range of clinical features clustered around comorbidities, clinical manifestations, and gender.

\section{Results}

Fourteen cross-sectional studies comprising of 4659 hospital patients were included in the systematic review. Thirteen of the studies were conducted in China (2025 patients) and one large study in New York (2634 patients). There were 2681 male participants (57.5\%) and the mean age was 59.8. Significant comorbidities reported across all patients were hypertension (43.6\%), diabetes (23.8\%) and coronary heart disease(CHD)/cardiovascular disease (12.4\%). The most prevalent clinical symptoms reported across all patients were: fever (88\%), fatigue $(44.5 \%)$ and myalgia (21.1\%). The mortality rate for hospitalised COVID-19 patients was $25.5 \%$ (1189 patients) with a higher risk for males (odds ratio [OR] 1.8; 95\%Cl 1.3-2.4, $\mathrm{p}=0.0003$ ) and older patients (mean difference [MD] 15.6\%; 95\% Cl 12.5-18.6, $\mathrm{p}<0.00001)$.

Fatigue was the only clinical symptom that had a clear association with mortality (OR $1.6 ; 95 \% \mathrm{Cl} 1.1$ $2.5, p=0.03)$. A statistically significant higher risk of mortality was identified for COVID-19 patients presenting with the following comorbidities: hypertension (OR 2.5;95\% CI 2.1-3.1; $p<0.00001$ ), diabetes (OR 2.0; 95\% Cl, 1.7-2.3; $\mathrm{p}<0.00001$ ), CHD/cardiovascular disease (OR 3.8; 95\%Cl 2.1-6.9, 
$\mathrm{p}=<0.00001)$, cerebrovascular disease (OR 4.9;95\% Cl 1.5-15.7, $\mathrm{p}=0.007)$ and chronic renal disease (OR 9.4; 95\% $\mathrm{Cl} 3.2-27.4, \mathrm{p}<0.0001$ ). Of these, the most prevalent amongst patients who died were hypertension (56.8\%), diabetes (31.2\%) and CHD/cardiovascular disease (21.5\%). No significant association was found between COPD or smoking and death although these were only reported in 4 studies.

Multiple disease biomarkers were statistically higher on admission for the non-survivor group compared to those who survived. These included markers for myocardial injury (cardiac troponin), heart failure (NT-proBNP), inflammatory processes, (interleukin-6, C-reactive protein, erythrocyte sedimentation rate) and liver/renal function (bilirubin, alanine transaminase, aspartate transaminase, creatinine, blood urea nitrogen and lower albumin). A higher rate of procalcitonin (a marker for sepsis), was also identified in the non-survivor group. There was a significantly greater risk of coagulopathy in the non-survivor group (lower platelet count) and the D-dimer measurements were higher. Biomarkers for immune cell counts also differed between survivors and non-survivors with the latter demonstrating a higher white blood cell count and a lower absolute lymphocyte and T cell count.

\section{Commentary}

Using the Joanna Briggs Institute Critical Appraisal tool for systematic reviews, ten out of the eleven criteria were judged to be satisfactory or not applicable for this review ${ }^{(7)}$. The criterion which was not achieved was the inclusion criteria, which was deemed inappropriate for the clinical question. Due to the lack of clarity for inclusion criteria related to population, it is unclear how hospitalised COVID-19 patients were defined. Subsequently, caution needs to be used when interpreting the results for completeness and external validity. Without specific definitions of these terms, it is unclear what was defined as hospital care and what methods of diagnosis were required to be classified as a COVID-19 patient.

This systematic review identified that a quarter of patients hospitalised with COVID-19 subsequently died and a significant proportion of these patients were men and older adults (on average 15 years older than the survival group). The two most prevalent comorbidities amongst hospitalised patients were hypertension (43.6\%) and diabetes (23.8\%) and of those patients who died, these comorbidities were present in $56.8 \%$ and $31.2 \%$ respectively. The odds of dying were 2.5 times more if hypertension was present and 2 times more for diabetes. $\mathrm{CHD} /$ cardiovascular disease was associated with a 3.8 times greater risk of mortality and was found to be present in approximately $12 \%$ of COVID-19 hospitalised patients. A recent systematic review ${ }^{(8)}$ concurs with these findings that older age, hypertension, and diabetes mellitus conferred a significantly increased risk of mortality. Therefore, the presence of these comorbidities may be used to help inform resource management, risk stratification and subsequent management of hospitalised COVID-19 patients.

The findings from the review suggest that the associations between cardiovascular disease and COVID-19 may be due to infection related ischemia leading to myocardial injury and/or viral induced inflammatory processes. Indeed, the results of the review showed that biomarkers for myocardial injury and increased inflammation were higher on admission in the non-survival group. Other biomarkers on admission suggested a greater prevalence of end organ dysfunction, inflammation and coagulopathy in those that did not survive. Similar findings were identified in a recent study of diabetes patients hospitalised with COVID-19. In the study, nearly all biological covariates reflecting COVID-19 severity were associated with death, including admission plasma glucose, plasma 
creatinine, AST, white cells, lymphocyte, platelet counts and CRP level ${ }^{(9)}$. This highlights the importance of admission biomarkers in identifying those at greater risk of mortality and providing appropriate treatment.

The review suggests that COVID-19 may have a direct effect on endothelial dysfunction and a subsequent reduction in the ability to produce nitric oxide, similar to other infections within the Severe Acute Respiratory Syndrome (SARS) family of viruses. The review implies that should an underlying endothelial dysfunction be present (an early event in hypertension, diabetes, CHD and kidney dysfunction) that it is possible for COVID-19 to cause further damage, leading to poorer outcomes and death. The authors acknowledge that further research in this area is required.

As new studies continue to be published in this priority area, systematic reviews should be regularly updated to build on the findings identified in other geographical areas. It is also important to clearly identify who the patients of the included studies are in terms of demographics, details of hospitalisation (including severity of condition on admission), location of patients within the hospital (COVID-19 ward or ICU) and how comorbidities/biomarkers are assessed and collected (patient record, swab test etc.). This will enable clearer recommendations to be made in the hospital management of COVID-19 patients.

\section{Acknowledgement}

This report is independent research funded by the National Institute for Health Research Applied Research Collaboration North West Coast (ARC NWC). The views expressed in this publication are those of the author(s) and not necessarily those of the National Institute for Health Research, the NHS, or the Department of Health and Social Care.

\section{References}

1. World Health Organisation . (2021). WHO Coronavirus Disease (COVID-19) Dashboard Available from: https://covid19.who.int/ ONS (2021).

2. Tian et al. (2020). Predicators of mortality in hospitalised COVID-19 patients: A systematic review and meta-analysis.

3. Yang J, Zheng Y, Gou X, et al. Prevalence of comorbidities in the novel Wuhan coronavirus (COVID-19) infection: a systematic review and meta-analysis. Int J Infect Dis. 2020.

4. Hu Y, Sun J, Dai Z, et al. Prevalence and severity of corona virus disease 2019 (COVID-19): A systematic review and meta-analysis. J Clin Virol. 2020;127:104371.

5. Kumar A, Arora A, Sharma $P$, et al. Is diabetes mellitus associated with mortality and severity of COVID-19? A meta-analysis. Diabetes Metab Syndr. 2020;14(4):535-545.

6. Pranata R, Huang I, Lim MA, Wahjoepramono PEJ, July J. Impact of Cerebrovascular and Cardiovascular Diseases on Mortality and Severity of COVID-19 - Systematic Review, Metaanalysis, and Meta-regression. J Stroke Cerebrovasc Dis. 2020:104949

7. Aromataris E, Fernandez R, Godfrey CM, Holly C, Khalil H, Tungpunkom P. 2015. Summarizing systematic reviews: Methodological development, conduct and reporting of an umbrella review approach. International journal of evidence-based healthcare. 13(3):132140. 
8. Mehraeen E, Karimi A, Barzegary A, Vahedi F, Afsahi AM, Dadras O, Moradmand-Badie B, Seyed Alinaghi SA, Jahanfar S. Predictors of mortality in patients with COVID-19-a systematic review. Eur J Integr Med. 2020 Dec;40:101226. doi: 10.1016/j.eujim.2020.101226. Epub 2020 Oct 17. PMID: 33101547; PMCID: PMC7568488.

9. Wargny, M., Potier, L., Gourdy, P. et al. Predictors of hospital discharge and mortality in patients with diabetes and COVID-19: updated results from the nationwide CORONADO study. Diabetologia (2021). https://doi.org/10.1007/s00125-020-05351-w 